\title{
Halka Açıklık Oranının Finansal Performans Üzerindeki Etkisi
}

\author{
Cüneyt Yenal KESBİÇ*
}

Beyza MIYNAT TAŞDEMIR**

$\ddot{o} Z$

Rekabetin yoğun yaşandığı günümüz ticaret hayatında firmaların önemli sorunlarından biride finansman sorunudur. Firmanlar finansman temin etmede alternatif yöntemler kullanir. Firmalar için kullanılan bu yöntemlerden biride halka arz yoluyla finansmandır. Halka arz olunan firmaların sermaye yapısı ve finansal performansa dayalı çıktıları değişim göstermektedir. Bu çalışmada da 2010-2018 yılları arasında BIST 100 Endeksinde yer alan 89 firmanın halka açıklık oranları ile finansal performans çıktıları arasındaki ilişki incelenmiştir. Bu bağlamda çalışmada bă̆ımsız değişken olarak firmaların mülkiyet yapısı hakkında fikir sahibi olmayı sağlayan halka açıklık oranı, bağımlı değiş̧en olarak aktif karlılık (ROA), öz sermaye karlılı̆̆ (ROE), kurumsal performans ölçütü Tobin's Q oranı ve yıllık hisse getirileri, kontrol değişkeni olarak ise kaldıraç oranı kullanılmıştır. Elde edilen analiz sonuçlarına göre halka açılılı oranı ile Tobin's $Q$ oranı arasında anlamlı ancak negatif bir iliş̧ki tespit edilmiş olup, diğer değişkenler ile anlamlı bir iliş̧k tespit edilememiştir.

Anahtar Kelimeler: Halka açıllık oranı, Tobin's Q, ROA, ROE.

Jel Siniflandırmast: G32, C23, L25

\section{The Effect Of Free Float Rate On Financial Performance}

\begin{abstract}
One of the important problems of companies in today's commercial life, where competition is intense, is the problem of financing. Firms use alternative methods of financing. One of the methods used for firms is financing through public offering. The capital structure and financial performancebased outputs of the public offering- held companies vary. In this study, the relationship between the free float rates and financial performance outputs of 89 firms included in the BIST 100 Index between 2010 and 2018 was examined. In this context, the ratio of free float which provides an idea about the ownership structure of firms as an independent variable, as the dependent variable, return on assets (ROA), return on equity (ROE), Tobin's $Q$ ratio and annual share returns also leverage ratio was used as control variable in this study. According to the results of the analysis, a significant but negative relationship was found between the free float ratio and Tobin's $Q$ ratio, besides there was no significant relationship with other variables.
\end{abstract}

Keywords: Free Float Rate, Tobin's q, ROA, ROE.

Jel classification: G32, C23, L25

\section{GíRIŞ}

Gelişmekte olan ülkelerde yaşanan sermaye yetersizliği söz konusu ülkelerin ekonomik büyüme ve kalkınma yolunda karşılaştı̆̆ en önemli sorunlar arasındadır. Küreselleşen Dünya'da, ülkeye uluslararası sahada rekabet avantajı

\footnotetext{
*Prof.Dr. Manisa Celal Bayar Üniversitesi, İktisadi ve İdari Bilimler Fakültesi, İktisat Bölümü,e mail:c.yenalkesbic@gmail.com

** Doktora öğrencisi, Manisa Celal Bayar Üniversitesi, İktisadi ve İdari Bilimler Fakültesi, İktisat Bölümü,e mail: beyzamiynat@gmail.com
} 
kazandıracak işletmelerin önünü açabilmek için ihtiyaç duyulan kaynaklarıntemin edilmesi konusunda sıkıntılar yaşanmaktadır. Bu bağlamda özellikle son yıllarda işletmelerin borsa şirketi olarak sermaye piyasasından finansman sağlamaları daha sık tercih edilmeye başlanmıştır. İşletmeler borsada işlem gören hisselerini finansman kaynağı sağlamak başta olmak üzere, kurumsallaşma, likidite yaratma, kredibilite arttırma, küreselleşme, yurt içi ve yurt dışında tanınma gibi amaçlarla halka arz etmektedir.

İşletmeler ekonomik faaliyetlerini sürdürürken sermaye yetersizliğinden kaynaklanan problemlerin çözümüne yönelik olarak farklı arayışları içerisine girmektedirler. İşletme bazında ihtiyaç duyulan sermaye temininde başvurulan temel iki yol vardır. Birinci yol öz kaynaklar (sermaye ve elde edilen varlıklar), ikincisi ise yabancı kaynaklardır. İşletmenin bu iki yoldan hangisini ne oranda seçeceğine ilişkin vereceği kararda, sermaye maliyetini minimize edecek optimal karışımı sağlaması gerekmektedir (Okka, 2010:412).

İşletmenin finansman açığı temininde uyguladığı yöntemlerden biride halka arz yoluyla hisse senedi ihraç etmesidir (Otlu ve Ölmez, 2011:15). İşletmeler ilk halka arz yolu ile ihtiyaç duydukları finansman kaynağını sermaye piyasasından temin etme şansına sahiptir. İşletmenin halka açılmasıyla kaynak ihtiyaçlarının temininde en uygun ve doğrudan finansman yöntemlerinden biridir (Brealey vd., 2007, 375). Halka açılma; halkın bir anonim şirkete katılmaya veya kurucu olmaya davet edilmesi ve hisse senetlerinin organize edilmiş piyasalarda sürekli işlem görmesi şeklinde tanımlanabilir (Akbulak, 2005:3).

$\mathrm{Bu}$ çalışmada da işletmelerin kaynak yetersizliği sorunuyla mücadele içerisinde olduğu Türkiye'de, sağladığı avantajlar göz önünde bulundurulduğunda oldukça teşvik edilen halka açılma ile finansal performans arasındaki ilişkinin incelenmesi amaçlanmıştır. Bu bağlamda 2010-2018 dönemi için BIST100'de yer alan ve verilerine ulaşılabilen 89 işletmenin halka açıklık oranlarının finansal performansları üzerindeki etkisini belirlemek için panel regresyon analizi yapılmıştır.

Çalışmanın ilk bölümünde halka açıklı oranının teorik çerçevesi belirlenmiştir. İkinci bölümde literatürde halka açıklık oranı ile finansal oranlar arasındaki ilişkiyi belirlemeye yönelik yapılan çalışmalara yer verilmiştir. Üçüncü bölümde ise çalışmanın uygulama kısmında kullanılan veri seti, analiz yöntemi ve hipotezlerden bahsedilmiştir. Dördüncü bölümde yapılan analizler sonucunda elde edilen bulgulara yer verilmiştir. Sonuç bölümünde çalışmanın bulguları literatürdeki yapılan çalışma sonuçları ile karşılaştırılarak değerlendirilmiştir.

\section{TEORİK ÇERÇEVE VE ÇALIŞMANIN AMACI}

\section{A. Teorik Çerçeve}

Halka arz, sermaye piyasası araçlarının satın alınması için her türlü yoldan halka çağrıda bulunulmasını; halkın bir anonim ortaklığa katılmaya veya kurucu olmaya davet edilmesini; hisse senetlerinin borsalar veya teşkilatlanmış diğer piyasalarda devamlı işlem göremesini; bu kanuna göre halka açı anonim ortaklıkların sermaye artırımları dolayısıyla paylarının veya hisse senetlerinin 
satışını ifade etmektedir (3794 Sayılı Kanunla Değişik 2499 Sayılı SPK M. 3/c) (Albez, 2003:75).

İşletmelerin halka açılmak için kullanabilecekleri üç temel yöntem vardır. Bunlardan birincisi mevcut hisse senetlerinin satışıdır. Burada, işletme sahip olduğu hisse senetlerinin bir kısmını halka satışını gerçekleştirir. İkinci yöntem, sermaye artırımı yoluyla halka arzdır. İşletmeler, yeni hisse senedini ihraç etmek için sermaye artırımına giderler ve böylelikle yeni finansman kaynağını elde etmiş olurlar. Üçüncü yöntem ise karma yöntem denilen, iki yöntemin birlikte kullanılmasıdır. $\mathrm{Bu}$ yöntemle, işletmeler mevcut hisse senetlerinin satışı ve sermaye artırımı yoluyla halka arzı gerçekleştirirler (Akkılıç ve Yıldırım, 2017:40).

Halka açıklık oranı farklı şekillerde tanımlansa da kısaca bir şirketin kamuya ihraç edilmiş, piyasada hiç bir sınırlamaya tabi olmadan alınıp satılabilen hisse senetlerinin şirketin toplam hisse senetlerine oranı olarak ifade edilebilir. $\mathrm{Bu}$ tanım bazen kurumsal yatırımcılar veya kamu kurumları gibi sahip oldukları hisse senetlerini piyasada çok sık pazarlamayan, durağan hissedarların sahip olduğu senetleri de dışlamak suretiyle daraltılmaktadır. (Bostancı ve Kılıç, 2010: 7) Ancak her halükârda, halka açıklık oranı işletmelerin önemli bir finansman kaynağından faydalanmak amacıyla hisselerinin ne kadarını halka arz ettiklerini göstermektedir.

Tanımlamadan da anlaşılacağı üzere işletmeler temel olarak finansman kaynağı temin etmek ve hisselerinin organize bir pazarda işlem görmesini sağlamak amacıyla halka açılmaktadır. Halka açılma alternatif finansman yöntemlerine göre daha düşük maliyetli olan, geri ödemesi olmayan ve işletmenin nakit akışını zorlayacak anapara ve faiz benzeri geri ödeme zorunlulukları barındırmayan bir kaynaktır. İşletmelerin halka açılarak sermaye yapıları kuvvetlendiği için borçlanma kapasiteleri de yükselmekte ve daha kolay kaynak bulmaları sağlanmaktadır. Bunun yanında işletmeleri halka açılmaya teşvik eden farklı nedenler de bulunmaktadır. Borsa İstanbul'da işletmelerin halka açılma nedenleri ve bu bağlamda elde edecekleri öngörülen avantajlar şu şekilde sıralanmaktadır'

Likidite: Halka arz edilen hisselerin organize bir pazarda istenilen zamanda, piyasa arz ve talebine göre oluşan fiyatlardan, şeffaflık ilkesiyle alınıp satılmasını sağlayarak hisselere likidite kazandırılmaktadır. Şirket ortakları Borsa'da işlem gören hisseleri kredi işlemlerinde teminat olarak da kullanabilmekte, atıl duran bu varlığı finansman yaratma aracina dönüştürebilmektedir.

1. Yurt içi ve yurt dışında yaygın tanıtım: Hisseleri Borsa'da işlem gören şirketler hakkındaki bilgiler, Borsanın şeffaflık ve kamuyu aydınlatma ilkesi çerçevesinde veri yayın kuruluşları ve basın/yayın kuruluşları aracılığıyla yurt içi ve yurt dışı yatırımcılara sürekli olarak ulaştırılmaktadır. Böylece işletmelerin hem yurt içinde hem de yurt dışında tanınması sağlanmaktadır. Bu sayede işletmeler aynı veya benzer sektörlerde faaliyet gösteren işletmeler ile işbirliği de yapabilmektedir.

\footnotetext{
${ }^{1}$ https://www.borsaistanbul.com/sirketler/halka-arz-ve-borsada-islem-gorme/pay-piyasasi/halka-arz/halkaarzin- faydalari-halka-arza-hazirlik-ve-halka-arz-surecleri, (15.05.2019)
} 
2. İkincil halka arz imkanı: İşletmeler birincil halka arz sonrasında hisseleri işlem görmekteyken yatırım ve benzeri ihtiyaçları nedeniyle ortaya çıkan kaynak gereksinimlerini, mevcut ortaklarının rüçhan haklarını kısıtlamak suretiyle gerçekleştirebilecekleri "İkincil Halka Arz" ile karşılayarak yeniden finansman imkan1 yaratabilmektedir.

3. Kurumsallaşma: Halka açılan işletmeler, sermaye piyasası disiplini içerisinde finansal ve diğer önemli bilgilerini kamuya duyurarak, düzenli ve zamanında raporlamalar yaparak, daha hızlı bir şekilde kurumsallaşabilmekte, yatırımcıların ve ortaklarının ilgisine ve gözetimine maruz kalmaları hasebiyle kurumsal yönetim ilkelerini daha kısa sürede özümseyebilmektedir.

4. Kredibilite: İşletmelerin Borsada işlem gören hisselerinin artması ile bankacılık ve para piyasası nezdindeki kredibiliteleri artmakta ve buna bağlı olarak kredi bulmaları kolaylaşmaktadır. Hisseleri Borsada işlem gören işletmelerin önemli verilerinin analiz edilmesi ve analiz sonuçlarına göre yayınlanan raporlar sayesinde yatırımcılar, kreditörler, tedarikçiler ve iş ortakları işletmeler hakkında bilgi sahibi olmaktadır. Bu sayede tanınırlığı artan işletmeler, finansman ve nitelikli insan kaynağı temininde, ürün ve hizmetlerinin pazarlanmasında ve yeni iş ortaklıklarının kurulması hususunda avantajlı konuma geçmektedir.

5. Küreselleşme: İşletmeler paylarının Borsada işlem görmeye başlaması ile birlikte yabancı ülkelerde de kolayca sermaye piyasası aracı ihraç edebilmekte ve o ülkede sermaye piyasası araçlarını kote ettirerek(borsa listesine aldırarak) işlem görmesini sağlayıp, yurt dışı piyasalara ulaşabilmektedirler.

Yukarıda açıklanan avantajlara ek olarak bankalarla pazarlık gücünün artması da gösterilebilir. Halka açılmayan bir işletmenin kredi değerini hesaplamak ya da bilmek çok da kolay değildir. Bankalar için bu tür işletmelerin kredi taleplerinin karşılanmasında daha fazla risk vardır. Bu nedenle, halka açılan bir işletmeye ilişkin bilgiler kreditörler ve yatırımcılar tarafından bilindiğinden risk faktörü burada azalmaktadır. Yani, işletmelerin bankalarla pazarlık gücü daha da artırmaktadır (Akkılıç ve Yıldırım, 2017:38).

İşletmelerin halka açılmasıyla elde ettikleri faydaların yanı sıra bir takım maliyetlere katlanmalarıyla ortaya bazı dezavantajlarda çıkmaktadır. Bu nedenle birçok işletme halka açılmadan faaliyetlerini sürdürmektedir. Halka açılmak isteyen bir işletmenin arz giderleri, düşük fiyatlama maliyeti, kamuoyunu sürekli olarak bilgilendirme gereksinimi gibi kabullenmesi gereken bazı maliyetleri de vardır (Erpek, 2006:14; Akkılıç ve Yıldırım, 2017:38).

Yukarıda açıklanan nedenlerden ötürü halka açılan işletmelerin finansal performanslarının akıbeti çalışmanın araştırma konusunu oluşturmaktadır. Çalışmada, sağladığı avantajlar göz önünde bulundurulduğunda işletmeler açısından oldukça makul görünen halka açılma stratejisinin BIST100 firmaları açısından değerlendirmesi yapılmıştır.

\section{B. Çalışmanın Amacı}

Günümüz ekonomik koşullarında sürekli olarak değişen ve gelişen işletmelerin rekabet etme güçleri kurumsal yapılarına ve finansal performanslarına 
göre değişkenlik göstermektedir. Şirket ortaklarının, yönetimde alınacak kararlara etkisi, sahip olunan hisse sayısına göre değişmekte olup, hisselerin büyük bölümünün belirli kişi ya da kurumların elinde olduğu, yani mülkiyet yoğunluğunun fazla olduğu durumlarda halka açıklık oranı önem kazanmaktadır. Bir işletmenin kurumsal yapısı konusunda bilgi veren en önemli gösterge olan halka açıklık oranın düşük ya da yüksek olmasının alınacak kararların hızını, maliyetini, işletmenin kârlılığııı ve dolayısıyla finansal performansını etkilediği öngörülmektedir (Çam, 2016: 520). Halka açıklık oranının finansal performans üzerindeki etkisi hususunda iki temel görüş bulunmaktadır. Bunlardan birincisi halka açıklık oranının düşük olması durumunda kurumsal yapının zayıf olması sebebiyle yönetici istismarı olasılığı artacağından yatırımcılardan gelen talebin azalacağı yönündedir. Talebin azalması ise hisse senedinin değerini düşürecektir. İkinci görüş ise halka açıklık oranı arttıkça yönetimde söz sahibi olan hissedarların hakları kısıtlanmakta ve bu durum işletmenin gelişmesi için alınan kararların verimliliğini etkilemektedir. Bu çalışmanın amacı Türkiye'de halka açılma oranının olası etkilerinin bu iki görüşten hangisini destekler nitelikte olduğunu tespit etmektir. Bu amaçla finansal performans ölçütü olarak aktif karlılık, öz sermaye karlılı̆̆1, Tobin's Q oranı, yıllık hisse getirileri ve bağımsız değişken olarak ise halka açıklık oranı ve kontrol değişkeni olarak finansal kaldıraç kullanılmıştır.

\section{LITERATÜR TARAMASI}

Firmaların finansal performanslarını değerlendirmek için farklı ölçütler kullanılmaktadır. Literatürde mülkiyet yapısı ile finansal performans arasındaki ilişkinin incelenmesine yönelik olarak ortaya konan ilk çalışmanın çıkış noktası iki değişken arasında negatif bir ilişki olması gerektiği savıyla 1932 yılında Berle ve Means tarafindan ortaya konmuştur. Bu çalışmaya karşılık olarak Demsetz 1983 yılında firmalarının mülkiyet yapılarının finansal performanslarını etkilediğini öne sürmüştür (Aytekin, 2014:119). Bu doğrultuda yapılan diğer araştırma sonuçları firmaların faaliyet gösterdiği ülke ve bölgelere göre farklılık arz etmekle birlikte son yıllarda literatüre kazandırılan bazı çalışmalar aşağıdaki tabloda özet halinde sunulmuştur. $\mathrm{Bu}$ çalışmalarda bir şirketin mülkiyet yapısı konusunda fikir veren halka açıklık oranı bağımsız değişken olarak kabul edilirken, bağımlı değişken olarak ROA, ROE, Tobin's Q, hisse senedi fiyatı ve hisse getirileri gibi finansal performans ölçütleri kullanılmıştır.

Tablo 1: Literatür Özeti

\begin{tabular}{|c|c|c|c|}
\hline Yazar & Borsa / Ülke / Veri aralığı & Yöntem & Sonuç \\
\hline Albez (2003) & $\begin{array}{c}\text { BIST } \\
(1995-2001)\end{array}$ & $\begin{array}{c}\text { Mali analiz } \\
\text { teknikleri }\end{array}$ & $\begin{array}{c}\text { Halka açılmanın firmaların finansal } \\
\text { yapılarına olumlu katk1 yapması } \\
\text { beklentisinin aksi yönünde sonuçlar } \\
\text { bulunmuştur. }\end{array}$ \\
\hline Wang ve Xu (2004) & Çin (1996-2002) & Regresyon analizi & $\begin{array}{c}\text { Halka açklık oranı ile hisse getirileri } \\
\text { arasında pozitif ilişki vardır. }\end{array}$ \\
\hline Barak (2007) & $\begin{array}{c}\text { IMKB } \\
(1997-2004)\end{array}$ & $\begin{array}{c}\text { Nokta biserial } \\
\text { korelasyon }\end{array}$ & $\begin{array}{c}\text { Halka açılılı oranı yükseldikçe hisse } \\
\text { senetlerinin fiyat değişimi azalmaktadır. }\end{array}$ \\
\hline Yörük (2006) & $\begin{array}{c}\text { İMKB } \\
(1998-2003)\end{array}$ & $\begin{array}{c}\text { Yatay Analiz, Oran } \\
\text { Analizi }\end{array}$ & $\begin{array}{c}\text { İşletmenin halka açılmasının finansal } \\
\text { performansı üzerinde olumlu etkileri } \\
\text { olduğuna sonucuna ulaşılmıştır. }\end{array}$ \\
\hline
\end{tabular}


Cüneyt Yenal Kesbiç \& Beyza Mıynat Tașdemir / Halka Açıklık Oranının Finansal Performans

Üzerindeki Etkisi

\begin{tabular}{|c|c|c|c|}
\hline Zeitun(2009) & $\begin{array}{c}\text { Ürdün } \\
(1989-2006)\end{array}$ & Regresyon analizi & $\begin{array}{c}\text { Mülkiyet yoğunlaşması ile firma } \\
\text { performansı arasında negatif korelasyon, } \\
\text { firma karlılığının firma performansı } \\
\text { üzerinde ise olumlu bir etkisi } \\
\text { bulunmaktadır. }\end{array}$ \\
\hline $\begin{array}{l}\text { Bayrakdaroğlu } \\
(2010)\end{array}$ & $\begin{array}{c}\text { İMKB } \\
(2005-2009)\end{array}$ & Panel regresyon & $\begin{array}{c}\text { Halka açıklık oranlarının finansal } \\
\text { performans üzerinde etkili olduğu tespit } \\
\text { edilmiştir. }\end{array}$ \\
\hline $\begin{array}{c}\text { Bostancı ve Kilıç } \\
\text { (2010) }\end{array}$ & İMKB (2007) & $\begin{array}{l}\text { Çoklu değişkenli } \\
\text { regresyon }\end{array}$ & $\begin{array}{l}\text { Hisse senedi getirileri ile halka açıklık } \\
\text { oranları arasında } \\
\text { pozitif ilişki vardır. }\end{array}$ \\
\hline \begin{tabular}{|c|} 
Sayılgan ve Sayman \\
$(2012)$
\end{tabular} & $\begin{array}{c}\text { İMKB } \\
(1998-2009)\end{array}$ & Panel veri analizi & $\begin{array}{l}\text { Halka açıklık oranının artmasıyla } \\
\text { kaldıraç oranı azalmıştır. }\end{array}$ \\
\hline Sorayaei vd. (2013) & $\begin{array}{c}\text { Tahran } \\
(2008-2009)\end{array}$ & Logit model & $\begin{array}{l}\text { Halka açıklık oranı ile fiyat balonu } \\
\text { arasında önemli bir ilişki tespit } \\
\text { edilmemiştir. }\end{array}$ \\
\hline \begin{tabular}{|c|} 
Çalışkan ve \\
Keresticioğlu (2013)
\end{tabular} & $\begin{array}{c}\text { BIST } \\
(2011-2012)\end{array}$ & Panel regresyon & $\begin{array}{l}\text { Halka açıklık oranı ile hisse fiyatı } \\
\text { arasında bir ilişki yoktur. }\end{array}$ \\
\hline $\begin{array}{l}\text { Aytekin ve İbiş } \\
\text { (2014) }\end{array}$ & $\begin{array}{c}\text { BIST } \\
(2009-2012)\end{array}$ & Panel regresyon & $\begin{array}{l}\text { Halka açıklık oranı ile ROA, ROE ve } \\
\text { Tobin's Q arasında anlamlı ve negatif } \\
\text { ilişki tespit edilmiştir. }\end{array}$ \\
\hline $\begin{array}{c}\text { Önem ve Demir } \\
(2015)\end{array}$ & $\begin{array}{c}\text { BIST } \\
(2009-2012)\end{array}$ & $\begin{array}{c}\text { Finansal oranlar } \\
\text { yöntemi }\end{array}$ & $\begin{array}{l}\text { Firmaların mülkiyet yapılarının finansal } \\
\text { aktif devir hızı, cari oran, öz sermaye } \\
\text { devir hızı ve Tobin's Q oranı üzerinde } \\
\text { pozitif yönde anlamlı bir etkisi varken, } \\
\text { fiyat-kazanç oranına ise negatif yönde } \\
\text { anlamlı bir etkisi çıkmıştır. }\end{array}$ \\
\hline $\begin{array}{l}\text { Doğan ve Topal } \\
\text { (2015) }\end{array}$ & $\begin{array}{c}\text { BIST } \\
(2002-2012)\end{array}$ & $\begin{array}{c}\text { Dirençli Tahminci } \\
\text { Yöntemleri }\end{array}$ & $\begin{array}{l}\text { Sahiplik yapısının işletmenin karlılığı, } \\
\text { piyasa değeri ve finansal başarısızlık } \\
\text { riski üzerinde etkili olduğu tespit } \\
\text { edilmiştir. }\end{array}$ \\
\hline Çam (2016) & $\begin{array}{c}\text { BIST } \\
(2010-2014)\end{array}$ & Panel regresyon & $\begin{array}{c}\text { Halka açıklık oranı ile karlılık } \\
\text { arasında anlamlı ve negatif bir ilişki } \\
\text { bulunmaktadır. }\end{array}$ \\
\hline $\begin{array}{c}\text { Aytekin ve Sönmez } \\
\text { (2016) }\end{array}$ & $\begin{array}{c}\text { BIST } \\
(2010-2014)\end{array}$ & Panel regresyon & $\begin{array}{l}\text { Halka açıklık oranı ile karlılık arasında } \\
\text { anlamlı bir ilişki vardır. }\end{array}$ \\
\hline $\begin{array}{c}\text { Topaloğlu ve Çoşkun } \\
\text { (2017) }\end{array}$ & $\begin{array}{c}\text { BIST } \\
(2009-2015)\end{array}$ & $\begin{array}{c}\text { Granger } \\
\text { Nedensellik Testi }\end{array}$ & $\begin{array}{c}\text { Aktif karlılık değişkeninde kısa dönemli } \\
\text { ilişkiler, aktif karlılığının bir dönem } \\
\text { gecikmeli değerleri, halka açıklık oranı } \\
\text { ve en büyük } 3 \text { ortağın sermaye payı } \\
\text { değişkenlerinin bir dönem gecikmeli } \\
\text { değerlerince belirlendiği tespit } \\
\text { edilmiştir. }\end{array}$ \\
\hline Salur vd. (2018) & $\begin{array}{c}\text { BIST } \\
(2011-2016)\end{array}$ & T-testi & $\begin{array}{c}\text { Halka açılma ile finansal performansları } \\
\text { arasında istatistiksel olarak anlamlı bir } \\
\text { ilişki olmadığı tespit edilmiştir }\end{array}$ \\
\hline $\begin{array}{l}\text { Eva ve Claudia } \\
\text { (2018) }\end{array}$ & $\begin{array}{l}\text { ABD } \\
(2016)\end{array}$ & $\begin{array}{c}\text { Doğrusal regresyon } \\
\text { analizi }\end{array}$ & $\begin{array}{l}\text { Halka açıklık oranı öz sermaye karlılığı } \\
\text { üzerinde anlamlı bir etkiye sahiptir. }\end{array}$ \\
\hline
\end{tabular}

Kaynak: şekil tarafimızca oluşturulmuştur.

Literatürde yer alan çalışmalar incelendiğinde halka açıklık oranının bağımsız değişken olarak kullanıldığı analiz sonuçlarının ülkeden ülkeye ve farklı örneklem gruplarında değişkenlik gösterdiği söylenebilmektedir. Bu değişkenliğin nedenlerinden biri ülkelerin işletme yapısındaki farklılıklardır. Örneğin, Türkiye'deki işletmelerin çoğunluğu aile ortaklı şirketler olduğu için işletmelerin başarısı ve yaşam ömrü, ailenin yönetimde yer alan üyelerinin ömürleri ve yönetim kabiliyetleri ile sınırlanmaktadır. $\mathrm{Bu}$ noktada halka açılmanın işletmenin 
kurumsallaşarak, daha yüksek bir performansa ve sürdürülebilir başarıya ulaşması için önemli bir adım olduğu öngörülmektedir. Halka açıklık oranının düşük olması durumunda hissedarın aynı zamanda yönetici olmasının yarattı̆̆ vekâlet maliyetinin yatırıma dair teşviği kırdığı söylenebilmektedir. Diğer taraftan da halka açıklık oranının yükselmesi işletmenin performansını arttıracak verimli kararlardan sapmaya yol açabilmektedir. Bu ikinci görüşte hissedar yöneticilerin söz hakkının kısıtlanması işletmenin yönetişim başarısı ve dolayısıyla finansal performans üzerinde olumsuz bir etki yaratabilmektedir. Bu çalışmada da incelenecek olan bu etkilerden hangisinin BIST100 firmaları için geçerli olduğudur.

\section{VERI SETI VE METODOLOJI}

\section{A. Değişkenlerin Tanımlanması}

Aktif karlılık (ROA), finansal tabloların analizinde en sık kullanılan ve bir şirketin kar elde etme başarısını gösteren orandır. Firmanın gelecekte de projelendirilebilir olması için geçmişteki kar elde etme kabiliyetini ölçmek için kullanılan önemli bir araçtır. Burada söz konusu varlıklar ana sermayenin kendisinden veya kurumsal sürdürülebilirlik için kullanılan şirket varlıklarından dönüştürülmüş yabancı sermayeden elde edilen genel şirket mülkiyetidir.

Öz kaynak kârlılı̆̆ (ROE), şirketin hisseye dayalı kar elde etme kabiliyetini şirkete ait sermayeye bağlı olarak ölçen karlılık oranıdır. Öz sermaye getirisi veya öz kaynak yenilenebilirliği olarak da ifade edilen bu oran diğer bir önemli finansal başarı ölçütüdür.

Tobin's Q kurumsal değeri belirlemeye yönelik araştırmalarda sıklıkla kullanılan bir performans ölçütü ve firmaların yatırım kararı alma sürecinde oldukça önem arz eden bir araçtır. Bu araştırmadaki kurumsal değerin ölçülmesi için de bu oranı kullanılmıştır.

Diğer bir bağımsız değişken hisse getirisi ise yatırım kararlarına göre farklılık gösteren bir değer olup, çalışmada işletmelerin yıllık bazda ki hisse getirileri, hisse fiyatlarının değişim oranının borsanın çalışma günü sayısına bölünmesi ile hesaplanmıştır.

İşletmenin toplam borç tutarının, varlıklara bölünmesiyle hesaplanan finansal kaldıraç ise bir yatırımın potansiyel getirisini arttırmak amacıyla finansal araçların ya da ödünç sermayenin kullanılması olarak tanımlanan ve varlıkların yüzde kaçının yabancı kaynaklar ile finanse edildiğini gösteren değerdir. İşletmenin finansman yapısı hakkında fikir edinmeyi sağlayan bu oranın genel olarak düşük olması tercih edilse de yabancı kaynak kullanımının öz sermaye miktarını arttırdığ 1 durumda, yani daha az sermaye ile öz sermaye karlılığının arttırılabilmesi söz konusu olduğunda nispeten yüksek bir değer alması olumlu karşılanabilir. Çalışmada literatürdeki örneklerden yola çıkılarak kontrol değişkeni olarak kullanılan bu oranın firmanın finansal performansına etkisi araştırılmaktadır.

Bağımsız değişken olarak kullanılan halka açıklık oranı (HAO), halka sunulmuş hisse senetlerinin nominal değerleri toplamının, hisselerin tamamının toplam nominal değerlerine oranı olarak tanımlanmaktadır. Çalışmada bu oranın, Türkiye'deki işletmelerin finansal performansı üzerindeki etkisi değerlendirilerek, günümüz sermaye piyasasında oldukça teşvik edilen bu yaklaşımın işletmeler 
açısından bir avantaj mı yoksa dezavantaj mı olduğu ortaya koyulmaktadır. Bu açıdan BIST100'de yer alan işletmeler baz alınarak oluşturulan bu çalışma halka açılma konusunda karar alınırken kılavuzluk edebilir.

Çalışmada kullanılan veriler Finnet Veri Tabanından derlenmiş olup, işletmelerin finansal tablolarından yararlanılarak elde edilen değerlerin hesaplama yöntemleri Tablo 2'de toplu halde gösterilmiştir. Bağımlı değişkenlerden Tobin's Q oranının oldukça farklı hesaplama teknikleri bulunsa da bu çalışmada literatürdeki örneklerden yola çıkılarak, toplam pasif kaleminden öz kaynakların çıkarılması ve şirketin piyasa değeri eklendikten sonra elde edilen değerin toplam aktife bölünmesi ile hesaplanmıştır. Modelin açıklama gücünü arttırmak adına işletmelerin finansal performanslarını etkilediği varsayılan kaldıraç oranı kontrol değişkeni olarak kullanılmıştır.

Tablo 2: Analizde Kullanılan Değişkenler

\begin{tabular}{|c|c|c|}
\hline \multirow{5}{*}{ Bağımlı Değişkenler } & Değișkenler & Hesaplama Yöntemi \\
\hline & Tobin's Q & kaynaklar + Piyasa Değeri) / Toplam Aktif \\
\hline & ROA & $\begin{array}{l}\text { Varlıkların Karlılığı Dönem Net Karı / } \\
\text { Toplam Aktif }\end{array}$ \\
\hline & ROE & $\begin{array}{l}\text { Öz kaynakların Karlılığı Dönem Net Karı / } \\
\text { Öz kaynaklar }\end{array}$ \\
\hline & Y1llık Hisse Getirileri (YHG) & $r_{y \text { llltk }}=\frac{\sum \frac{p_{t}-p_{t-1}}{p_{t-1}}}{252}$ \\
\hline Bağımsız Değişken & $\begin{array}{l}\text { Halka Açıklık Oranı } \\
\text { (HAO) }\end{array}$ & $\begin{array}{l}\text { Halka Açık Sermaye Tutarı / Toplam Öz } \\
\text { kaynaklar }\end{array}$ \\
\hline Kontrol Değişkeni & Kaldıraç Oranı & Toplam Borç / Toplam Varlık \\
\hline
\end{tabular}

\section{B. Metodoloji}

Çalışmada halka açıklık oranının finansal performans üzerindeki etkisinin belirlenmesi için 4 ayrı hipotez oluşturulmuştur. Hipotezler kurulurken literatürde yer alan çalışmaların sonuçları takip edilerek, halka açıklık oranının olası etkileri göz önünde bulundurulmuştur. Bağımsız değişken olan halka açıklık oranının bağımlı değişkenler üzerindeki etkisi ayrı ayrı incelenmiştir. $\mathrm{Bu}$ doğrultuda oluşturulan hipotezler:

H1: Yüksek halka açıklık oranı aktif karlılık oranını arttırır.

H2: Yüksek halka açıklık oranı öz sermaye karlılık oranını arttırır.

H3: Yüksek halka açıklık oranı Tobin's Q oranını arttırır.

H4: Yüksek halka açıklık oranı hisse getirilerini arttırır.

Bu çalışmada BIST 100'de yer alan ve verilerine ulaşılabilen 89 firmanın 2010-2018 yılları arasındaki finansal verilerinden faydalanılmıştır. Çalışmada dengesiz panel veri seti kullanılmıştır. Çalışmanın analizi gerçekleştirilirken Eviews programından yararlanılmıştır. Panel veri analizinde kat sayı tahmini yapılırken havuzlandırılmış regresyon modeli, sabit etkiler modeli ve rassal etkiler yöntemi olmak üzere temel olarak 3 ayrı yaklaşımdan faydalanılmaktadır. Bu çalışmanın analiz bölümünde hangi yaklaşımın seçileceğine karar verebilmek için Hausman testi uygulanmıştır. Bu test ile rassal etkiler yöntemine göre belirlenen katsayılar ile sabit etkiler yöntemine göre belirlenen katsayılar karşılaştırılmaktadır. Çıkan sonuçlar karşılaştırıldığında katsayılar arasında 
herhangi bir ilişkiye rastlanmazsa $(\mathrm{p}>0.05)$ rassal etkiler yaklaşımı, katsayılar arasında bir ilişki söz konusu ise $(\mathrm{p}<0.05)$ sabit etkiler yaklaşımının kullanılması gerekmektedir (Sarıkovanlik vd, 2019:179).

Hipotezlerin testi bölümünde görüleceği üzere Hausman testi sonucunda rassal etki yaklaşımının kullanılmasına karar verilmiştir. Rassal etkiler yaklaşımında otokorelasyon olup olmadığını kontrol etmek için ise BhargavaFranzini Narendranathan'ın Durbin-Watson testi kullanılmıştır. Yapılan test sonucunda elde edilen değer 2'den çok küçük ise pozitif otokorelasyon, 2'den çok büyük ise negatif otokorelasyon olduğu sonucuna ulaşılmaktadır. $\mathrm{Bu}$ analizde korelasyon ilişkisi ve tanımlayıcı istatistiklerin değerlendirilmesi yapıldıktan sonra otokorelasyon probleminin ortadan kaldırılması ve serilerin standardize olması için verilerin yıllık değişim yüzdeleri hesaplanarak modelleme yapılmıştır.

\section{BULGULAR}

Analize ilk olarak değişkenler arasındaki korelasyon ilişkisinin araştırılması ile başlanmıştır. Tablo 3'de bağımlı ve bağımsız değişkenlere ilişkin korelasyon katsayılarına yer verilmiştir.

Tablo 3: Değişkenler Arasındaki Korelasyon İlişkisi

\begin{tabular}{|l|c|c|c|c|c|c|}
\hline & HAO & KALD. & ROA & ROE & TBN-Q & YHG \\
\hline HAO & 1 & -0.0195 & -0.0789 & -0.0013 & -0.0422 & 0.0194 \\
\hline KALD & -0.0195 & 1 & -0.1896 & -0.0641 & 0.0477 & -0.008 \\
\hline ROA & -0.0789 & -0.1896 & 1 & 0.2674 & 0.2274 & 0.1850 \\
\hline ROE & -0.0013 & -0.0641 & 0.2674 & 1 & 0.0530 & 0.0752 \\
\hline TB-Q & -0.0422 & 0.0477 & 0.2274 & 0.0530 & 1 & 0.2904 \\
\hline YHG & 0.0194 & -0.0083 & 0.1850 & 0.0752 & 0.2904 & 1 \\
\hline
\end{tabular}

Buna göre, araştırmada kullanılan bağımsız değişkenler arasında yüksek derecede korelasyona rastlanmamıştır. Buna bağlı olarak, halka açıklık oranı ile performans ölçütleri arasındaki ilişkinin anlamlı olduğu söylenebilmektedir. Bağımsız değişkenler arasındaki ilişkinin de \%50'nin altında katsayı değerleri alarak anlamlı çıktığı görülmektedir.

Tablo 4: Değişkenlere Ait Tanımlayıcı istatistikler

\begin{tabular}{|l|l|c|r|r|r|c|}
\hline & HAO & KALD. & ROA & ROE & YHG & TBNQ \\
\hline Min & 0 & 0 & -35.84 & -1987.03 & -80.919 & 0.14 \\
\hline Max & 100 & 1.140 & 92.8 & 1090.97 & 543.421 & 10.11 \\
\hline Mean & 34.757 & 0.444 & 5.590 & 11.126 & 22.586 & 1.328 \\
\hline Std. dev & 18.308 & 0.274 & 9.606 & 82.828 & 60.181 & 0.883 \\
\hline Gözlem sayısı: 801
\end{tabular}

Tablo 4 incelendiğinde BIST100'de yer alan 89 firmanın halka açıklık oranı ortalamasının $\% 34.75$ olduğu ve en düşük firmanın $\% 0$, en yüksek firmanın ise \%100 oranında hisse senetlerini halka arz ettiği görülmektedir.

Çalışmada zaman boyutunun yer alması nedeniyle serinin zaman içerisinde durağan olup olmadığını ölçmek için Levin, Lin\&Chu t*, IPS ve Fisher ADF\&PP testlerinin özet gösterimini içeren birim kök testi uygulanmış ve bütün serilerin düzeyde durağan oldukları sonucuna ulaşılmıştır. Tablo 5' de özet olarak durağanlık test sonuçlarına yer verilmiştir. 
Cüneyt Yenal Kesbiç \& Beyza Mıynat Taşdemir / Halka Açıklık Oranının Finansal Performans Üzerindeki Etkisi

Tablo-5: Durağanlık Testi Sonuçları

\begin{tabular}{|c|c|c|c|c|c|c|c|c|}
\hline \multirow{2}{*}{$\begin{array}{c}\text { DÜZEY } \\
+ \\
\text { SABÍT }\end{array}$} & \multicolumn{2}{|c|}{ Levin, Lin \& Chu t* } & \multicolumn{2}{|c|}{$\begin{array}{c}\text { Im, Pesaran and Shin } \\
\text { W-stat }\end{array}$} & \multicolumn{2}{|c|}{ ADF - Fisher Chi- square } & \multicolumn{2}{|c|}{ PP - Fisher Chi- square } \\
\hline & $P$ & Ist. & $P$ & Ist. & $P$ & $\dot{I s t}$. & $P$ & Ist. \\
\hline HAO & 0.000 & -6.634 & 0.008 & -2.368 & 0.000 & 117.7 & 0.000 & 305.7 \\
\hline KALD. & 0.000 & -11.25 & 0.013 & -2.200 & 0.003 & 210.0 & 0.000 & 498.5 \\
\hline ROA & 0.000 & -10.15 & 0.000 & -3.139 & 0.000 & 257.5 & 0.000 & 618.4 \\
\hline ROE & 0.000 & -128.9 & 0.000 & -10.29 & 0.000 & 271.4 & 0.000 & 623.1 \\
\hline TBNQ & 0.000 & -6.275 & 0.000 & -4.282 & 0.000 & 282.9 & 0.000 & 863.4 \\
\hline YHG & 0.000 & -66.18 & 0.000 & -5.890 & 0.001 & 219.4 & 0.000 & 484.7 \\
\hline
\end{tabular}

Analizde bağımsız değişkenin, bağımlı değişkenler üzerindeki etkisini bulmak için 4 ayrı hipotezin test edilmesi amaciyla 4 tane model kurulmuştur:
(1)Model-1: $\mathrm{ROA}_{\mathrm{it}}=\alpha_{\mathrm{it}}+\beta_{1} \mathrm{HAO}_{\mathrm{it}}+\beta_{2} \mathrm{KAL}_{\mathrm{it}}+\varepsilon_{\mathrm{it}}$
$\mathrm{i}=1, \ldots, \mathrm{N} \quad \mathrm{t}=1, . ., \mathrm{T}$
(2)Model-2: $\mathrm{ROEi}_{\mathrm{t}}=\alpha_{\mathrm{it}}+\beta_{1} \mathrm{HAO}_{\mathrm{it}}+\beta_{2} \mathrm{KAL}_{\mathrm{it}}+\varepsilon_{\mathrm{it}}$ $\mathrm{i}=1, . . \mathrm{N} \quad \mathrm{t}=1, \ldots, \mathrm{T}$
(3)Model-3: Tobin $_{\text {it }}=\alpha_{\mathrm{it}}+\beta_{1} \mathrm{HAO}_{\mathrm{it}}+\beta_{2} \mathrm{KAL}_{\mathrm{it}}+\varepsilon_{\mathrm{it}}$
(4)Model-4: $\mathrm{YHG}_{\mathrm{it}}=\alpha_{\mathrm{it}}+\beta_{1} \mathrm{HAO}_{\mathrm{it}}+\beta_{2} \mathrm{KAL}_{\mathrm{it}}+\varepsilon_{\mathrm{it}}$ $\mathrm{i}=1, ., \mathrm{N} \quad \mathrm{t}=1, \ldots, \mathrm{T}$ $\mathrm{i}=1, ., \mathrm{N} \quad \mathrm{t}=1, . ., \mathrm{T}$

Finansal performans ölçütü olarak ROA değişkeninin bağımlı değişken olarak kullanıldığı eşitlik Model-1, ROE'nin bağımlı değişken olarak kullanıldığ 1 eşitlik Model-2, Tobin's Q'nun kullanıldığ eşitlik Model-3 ve son olarak yıllık hisse getirilerinin bağımlı değişken olduğu eşitlik ise Model-4 olarak tanımlanmıştır. Standardize edilen serilerden oluşturulan panel regresyon modellerinin analiz edilmesinde, iki temel yaklaşım olan sabit etki ve rassal etkiden hangisinin kullanılacağı Hausman testiyle belirlenmiştir. Buna bağlı olarak oluşturulan her modele ait Hausman test sonuçları tablo halinde aşağıda gösterilmiștir.

Tablo 6: Modellerde Kullanılacak Yaklaşımın Belirlenmesine Yönelik Test

\begin{tabular}{|c|c|c|l|}
\hline \multicolumn{5}{|c|}{ HAUSMAN TESTI } \\
\hline \multicolumn{5}{|c|}{ Model-1 } \\
\hline Test Summary & Chi-Sq.Statistic & Chi-Sq.d.f. & Olas1lik \\
\hline Cross-section random & 2.007 & 2 & 0.3666 \\
\hline \multicolumn{5}{|c|}{ Model-2 } \\
\hline Test Summary & Chi-Sq.Statistic & Chi-Sq.d.f. & Olas1lik \\
\hline Cross-section random & 1.873 & 2 & 0.3919 \\
\hline \multicolumn{5}{|c|}{ Model-3 } \\
\hline Test Summary & Chi-Sq.Statistic & Chi-Sq.d.f. & Olas1lik \\
\hline Cross-section random & 1.743 & 2 & 0.4182 \\
\hline \multicolumn{5}{|c|}{ Model-4 } \\
\hline Test Summary & Chi-Sq.Statistic & Chi-Sq.d.f. & Olas1lik \\
\hline Cross-section random & 1.464 & 2 & 0.4807 \\
\hline
\end{tabular}

Tablo 6' da yer alan Hausman test sonuçlarına göre 4 model için de olasıllk değerleri 0,05 'den büyük çıkmıştır. Bu sebeple analiz aşağıdaki $\mathrm{H}_{0}$ hipotezi kabul edilerek yorumlanmıştır.

$\mathbf{H}_{\mathbf{0}}$ : $\mathrm{E}($ cit $\mid \mathrm{Xit})=0$ kesit verisi ve zaman serisi etkileri rastsaldır.

Rassal etki yaklaşımına göre uygulanan panel regresyon sonuçları ise her model için ayrı tablolar halinde gösterilmiştir. 
Yönetim ve Ekonomi 26/2 (2019) 689-703

Tablo 7: Model-1 Panel Regresyon Sonuçları

\begin{tabular}{|c|c|c|c|c|}
\hline Bağımsız Değişken & Katsayı & Std. Hata & t-ist. & Olasılık \\
\hline HAO & -0.416 & 0.695 & -0.599 & 0.5492 \\
\hline KALDIRAÇ & -1.633 & 1.123 & -1.454 & 0.1463 \\
\hline DW=2.297706 & \multicolumn{3}{|c|}{ F testi=1.260158 } & F olasılık=0.284338 \\
\hline
\end{tabular}

İlk olarak Model-1'in yer aldığı Tablo 7‘de görüleceği üzere, bağımlı değişkenin ROA olması durumunda modelin olasılık ve anlamlılık düzeyinin 0.05 'ten oldukça büyük bir değer aldığı görülmektedir. Burada, HAO ve KALDIRAÇ değiş̧kenleri ile bağımlı değişken arasında istatistiksel olarak anlamlı bir ilişki tespit edilememiştir.

Tablo 8: Model-2 Panel Regresyon Sonuçları

\begin{tabular}{|c|l|c|c|c|}
\hline $\begin{array}{l}\text { Bağımsız } \\
\text { Değişken }\end{array}$ & Katsayı & Std. Hata & t-ist. & Olasılık \\
\hline HAO & -0.630 & 0.550 & -1.145 & 0.252 \\
\hline KALDIRAÇ & -0.498 & 0.887 & -0.561 & 0.574 \\
\hline DW=2.183515 & F testi=0.832838 & F olasılık=0.435307 \\
\hline
\end{tabular}

Model 2'ye ait panel regresyon sonuçları Tablo 8`de yer almaktadır. İlk modelde olduğu gibi buradaki değişkenler arasında da istatistiksel olarak anlamlı bir ilişki tespit edilememiştir.

Tablo 9: Model-3 Panel Regresyon Sonuçları

\begin{tabular}{|c|r|c|l|c|}
\hline Bağımsız Değişken & Katsayı & Std. Hata & t-ist. & Olasılık \\
\hline HAO & -0.049 & 0.021 & -2.333 & 0.019 \\
\hline KALDIRAÇ & 0.019 & 0.034 & 0.572 & 0.567 \\
\hline DW=2.395064 & \multicolumn{2}{|c|}{ F testi=3.12977 olasilık $=0.044423$} \\
\hline
\end{tabular}

Tobin's Q'nun bağımlı değişken olarak kullanıldığı Model-3'de ise HAO ile finansal performans arasinda istatistiksel olarak nispeten anlamlı ve negatif bir ilişki tespit edilmiştir. Modelin anlamlılı̆̆ını gösteren " $F$ " olasılık değerinin de 0.05 'in altında bir değer aldığ 1 görülmektedir.

Tablo 10: Model-4 Panel Regresyon Sonuçları

\begin{tabular}{|c|c|c|l|c|}
\hline Bağımsız Değişken & Katsayı & Std. Hata & t-ist. & Olasılık \\
\hline HAO & 7.139 & 11.915 & 0.599 & 0.549 \\
\hline KALDIRAÇ & -0.835 & 19.229 & -0.043 & 0.965 \\
\hline \multicolumn{3}{|c|}{ DW=2.316545 } \\
\hline F testi=0.181452 F olasilik=0.834103 \\
\hline
\end{tabular}

Son olarak Tablo 10 'da Model-4'e ait sonuçlara yer verilmiştir. Yıllık hisse getirilerinin bağımlı değişken olarak kullanıldığı modelde halka açıklık oranı ile yıllık hisse getirileri arasında anlamlı bir ilişki tespit edilememiştir.

Böylece analiz sonuçlarına göre oluşturulan hipotezler arasından " $\mathrm{H} 3$ : Yüksek halka açıklık oranı Tobin's Q oranını arttırır." hipotezi reddedilmiştir. Çalışmadan elde edilen H3 hipotezine ait bulgular (Bayraktaroğlu,2010:17)'de elde edilen bulguları ile benzerlik göstermektedir. Diğer bir ifade ile mülkiyet yapısındaki yoğunlaşma arttıkça finansal performans seviyesinde de artışlar yaşanmaktadır. 
Diğer hipotezler ise regresyon sonuçları istatistiksel olarak anlamsız çıktığı için desteklenememektedir. Kontrol değişkeni olarak kullanılan kaldıraç oranının da bağımlı değişkenler ile bir ilişkisi bulunamamıştır.

\section{SONUÇ}

Türkiye'de işletmelerin çoğunun aile ortaklı olması sebebiyle işletme yapısının kurumsallaşmaktan uzaklaşarak, finansal performansının düşebileceği öngörülmektedir. Halka açılma sayesinde ise işletmelerin kurucu ortaklardan bağımsızlaşarak profesyonelleşeceği ve sürdürülebilir başarıya ulaşabilecekleri kabul edilmektedir. Bu noktadan hareketle çalışmada halka açıklık oranı ile finansal performans arasındaki ilişki araştırılmış olup, halka açıklık oranının finansal performansı arttıracağ1 yönünde hipotez kurulmuştur.

Analiz sonuçları genel hatlarıyla değerlendirildiğinde ise öncelikle Türkiye'de halka açıklık oranının hala düşük seviyelerde olduğu söylenebilmektedir. İşletmeler borçlanmak yerine halka açılarak finansman elde etme politikasını henüz tam anlamıyla özümseyebilmiş değillerdir. Diğer taraftan halka açıklık oranı arttıkça finansal performansın ölçütü olan Tobin's Q oranının düştüğü görülmektedir. Yapılan analizlerde halka açıklık oranı ile Tobin's Q oranı arasında ters ancak anlamlı bir ilişki bulunmaktayken, halka açıklık oranının diğer değişkenler üzerindeki etkisi anlamlı değildir.

Halka açıklık oranıyla mülkiyet yoğunluğu ters ilişki içerisindedir. Diğer bir ifadeyle halka açıklık oranı arttıkça mülkiyet yoğunluğu azalmakta ve halka açıklık oranı azaldıkça mülkiyet yoğunluğu artmaktadır. Bu bağlamda halka açıklık oranı yüksek, dolayısıyla mülkiyet yoğunluğu düşük olan işletmeler genel olarak profesyonel bir yönetime sahip olup, bu işletmelerin yöneticilerinin varlıkları ve öz kaynakları daha verimli yönettikleri varsayılmaktadır. Bunun aksine teorik olarak yöneticilerin hissedar olmadığı veya işletmelerin halka açılarak hissedarların mülkiyet haklarının kısıtlandığı durumlarda yönetimin işletmenin gelişmesi için gerekli motivasyona sahip olamayacağı ve dolayısıyla şirketin piyasa değerini yükseltmek adına yeterli çabayı sarf etmeyecekleri de varsayımlar arasındadır. Bu çalışmada halka açıklık oranı arttıkça firmanın piyasa değerinin göstergesi olarak kullanılan Tobin's Q oranının düştüğü gözlemlenmiş olup, ikinci teoriyi destekleyen bir sonuç ortaya konmuştur. Ancak çalışmada işletmelerin ortaklık yapısı göz önünde bulundurulmadan analiz yapılmıştır. Yönetici sahipliği ve yabancı sermaye payı gibi bağımsız değişkenlerin de analize dahil edilmesi ekonometrik modellerin açıklama gücünü arttırabilir.

\section{KAYNAKÇA}

Akbulak, S. ve AKBULAK, Y. (2005). Türkiye'de Sermaye Piyasası Araçları ve Halka Açık A.Ş. , İstanbul: Beta Basım A.Ş.

Akk1lıc, M.E. and y1ldırım, H.H. (2017). The effect of optimum pricing for the initial public offerings on the return of stocks: evidence from Istanbul Tock Exchange for 2014-2016. Journal of Economics, Finance and Accounting (JEFA), V.4, Iss.1, p.37-47.

Albez, A. (2003). Halka Açılmanın Anonim Şirketlerin Finansal Yapısı Üzerindeki Etkileri, Yayımlanmış Doktora Tezi, Atatürk Üniversitesi, Sosyal Bilimler Enstitüsü, İşletme Anabilim Dalı, Erzurum. 
Aytekin, M. ve Sönmez, R. (2016). Kurumsal Yönetim Uygulamalarının İşletme Performansına Etkisi, Türk Sosyal Bilimler Araştırmaları Dergisi, 1(2): 32-41.

Aytekin, S. ve İBİŞ, A. (2014). Mülkiyet Yapısının İşletmelerin Finansal Performansı Üzerindeki Etkilerinin Değerlendirilmesi: BIST Metal Eşya, Makina Endeksi (XMESY) Üzerinde Bir Uygulama, Dumlupinar Üniversitesi Sosyal Bilimler Dergisi, (40), 119-130.

Barak, O. (2007). Hisse Senedi Piyasasında Halka Açıklık Oranının Piyasa Fiyatı Üzerine Etkisi, Sosyal Bilimler Meslek Yüksekokulu Dergisi, 10(1-2): 59-70.

Bayrakdaroğlu, A. (2010). Mülkiyet Yapısı ve Finansal Performans: İMKB Örneği, Ekonomi Bilimleri Dergisi, 2(2): 11-20.

BERLE, Adolf and Gardiner MEANS (1932). The Modern Corporation and Private Property, Harcourt, Brace, \& World, New York.

BORSA İSTANBUL A. Ş. https://www.borsaistanbul.com/sirketler/halka- arz-ve-borsada-islemgorme/pay-piyasasi/halka-arz/halka-arzin-faydalari-halka- arza-hazirlik-ve-halka-arzsurecleri, (15.05.2019).

Bostancı, F. ve kılıç, S. (2010). Şirketlerde Halka Açıklık Oranının Piyasa Performansına Etkisi: İstanbul Menkul Kıymetler Borsası Üzerine Ampirik Bir Çalışma, IMKB Dergisi. 12(45): $1-14$.

Brealey, R. A., Myers, S.C. ve Marcus, A.J. (2007). İşletme Finansının Temelleri, ISBN 975-843156-0, Literatür Yayınc1lık, İstanbul.

Çalışkan, T. ve Keresticioğlu, S. (2013). Effects of Free Float Ratios on Stock Prices: An application on ISE, Doğuş Üniversitesi Dergisi. 14(2):165-174.

Çam, A. V. (2016). Halka Açıklık Oranının Firmanın Karlılı̆̆ına Etkisi: Tekstil Sektöründe Bir Araştırma, Uluslararası Yönetim İktisat ve Işsletme Dergisi, ICAFR 16 Özel Sayısı, 519-531.

Doğan, M. ve Topal, Y. (2015). Sahiplik Yapısının Firma Performansı Üzerine Etkisi: Türkiye Örneği, Süleyman Demirel Üniversitesi İktisadi ve İdari Bilimler Fakültesi Dergisi, 20(4).

Eva, L. T. ve Claduia, N. M. (2018). Effect of Free Float Ratio on the Behavior of Shares Valuation in Companies Listed in Latin American Capital Market, Firm Value - Theory and Empirical Evidence. (https://cdn.intechopen .com/pdfs/60927.pdf, 04.05.2019)

Okka, O. (2010). Finansal Yönetim; Teori ve Çözümlü Problemler, ISBN 978-975-591-821-1, Nobel Yayınevi, Ankara.

Otlu, F. ve Ölmez, S. (2011). Halka ilk kez arz edilen hisse senetlerinin kısa dönem fiyat performansları ile fiyat performansını etkileyen faktörlerin incelenmesi, İMKB'de bir uygulama. Akademik Yaklaşımlar Dergisi, 2(2), 14-44.

Önem, H. B. ve Demir, Y. (2015). Mülkiyet Yapısının Firma Performansına Etkisi: BIST İmalat Sektörü Üzerine Bir Uygulama. Süleyman Demirel Üniversitesi Vizyoner Dergisi, 6(13), $31-43$.

Romer, D. (1996). Advanced Macroeconomics, 4th Edition, McGraw-Hill Series Economics: New York, Lisbon, London, Madrid, Milan.

Salur, M. N., Demirci, M. N. ve Kesen, B. (2018) KOBİ'lerde Halka Açılmanın Finansal Performansa Etkisi: BİST Gelişen İşletmeler Piyasasında Bir Uygulama, Işsletme Araştırmaları Dergisi, DOI: 10.20491/isarder.2018.371.

Sarıkovanlık, V., Koy, A., Akkaya, M., Yıldırım, H.H. ve Kantar, L. (2019). Finans Biliminde Ekonometri Uygulamaları, Seçkin Yayıncılık, Ankara.

Sayılgan, G. ve Sayman Y. (2012), İmalat Şirketlerinin Ortaklık Yapılarının, Finansman Kararları Üzerindeki Etkisi: İMKB Uygulaması, IMKB Dergisi, Cilt: 12, Sayı: 48.

Sorayaeı, A., Memarıan, E. ve Amırı, M. O. (2013). Examine the Relationship Between Free Float of Shares and P/E Ratio with a Price Bubble in the Companies Listed in Tehran Stock Exchange, World Applied Sciences Journal, 21 (2): 170-175.

Topaloğlu, E. E. ve Çoşkun, N. (2017). Firma Karlılığını Etkileyen Faktörlerin Sahiplik Yoğunlaşması Doğrultusunda Tespiti: Ampirik Bir Yaklaşım, Süleyman Demirel Üniversitesi İ̈BF, 22(1), 95-112.

Wang, F. ve Xu, Y. (2004). What Determines the Chinese Stock Returns?, Financial Analyst Journal, 60, 65-77. 
Yörük, N. (2006). Aile şirketlerinde kurumsallaşma ve halka açılmanın finansal performans üzerine etkisi: halka açı bir aile şirketi üzerinde vaka çalışması, Sosyal Ekonomik Araştırmalar Dergisi, 6(12), 180-202.

Zeitun, R. (2009). Ownership Structure, Corporate Performance and Failure: Evidence From Panel Data of Emerging Market The Case of Jordan, Corporate Ownership and Control, 6(4), 96.

\section{SUMMARY}

The capital shortage experienced in developing countries is one of the most important problems faced by developing countries in the path of economic growth and development. In the globalizing world, there are problems in providing the necessary resources to pave the way for the enterprises that gain competitive advantage in the international area. In this context, especially in recent years, it has become more preferable for businesses to provide financing from the capital market as a stock exchange company. The companies offer their shares traded on the stock exchange to the public for the purposes of financing, institutionalization, liquidity creation, increase in credibility, globalization, and recognition at home and abroad.

Turkey is the one of the country that struggle with lack of resources and public offering is encouraged by the state. Concordantly, it is aimed to investigate the relationship between FFR and the financial performance.

Most of the businesses are family partnership in Turkey. However, it is foreseen that the financial structure of the enterprise may be deteriorated from the institutionalization. Through public offering, it is recognized that if businesses become independent from the founding partners, they may become more professional and achieve sustainable success. From this point of view, the relationship between free float ratio and financial performance have been investigated in this study and hypothesis have been established that high free float ratio would improve financial performance. In this analysis, the free float rate has been used as the variable of ownership structure like another studies in the literature. As a dependent variable, asset profitability (ROA), equity profitability (ROE), Tobin's q ratio (corporate performance criterion) and annual share returns have been used. Also financial leverage ratio has been used as control variable. As a result of the analysis, a significant and negative relation has been found between free float ratio and Tobin's q ratio. But there has been no significant relationship between the other variables. The data set has been consisted of 89 firms in BIST100 between 2010-2018 and considering the results of the analysis outlined above, it can be said that free float ratio is still low level in Turkey. Businesses have not fully adopted the policy of obtaining public funding rather than borrowing.

Free float ratio and property density are inversely related. In other words, as the free float rate increases, property density decreases and as the free float rate decreases, property density increases. In this context, enterprises with high free float ratio and thus low ownership density generally have a professional management and it is assumed that the managers of these enterprises manage their assets and equity more efficiently. On the contrary, it is the assumption that management cannot have the necessary motivation for the development of the 
enterprise and that it will not make sufficient efforts to increase the market value of the company. in cases where the managers are not shareholders or the companies' ownership rights are restricted by going public. According to the result of this analysis, it has been determined that when the free float ratio increases, Tobin's q ratio -which is used as an indicator of the market value of the firm- decreases and this conclusion supports the other studies in the literature. However, the analysis was conducted without considering the partnership structure of the enterprises. If it is included different independent variables in analysis, for instance executive ownership and share of foreign capital, the explanatory power of econometric models may increase. Concordantly, this study leads up the other intended studies about the relation between free float ratio and financial performance. 